\title{
Evaluasi Program Sarjana Membangun Desa (SMD) dan Strategi Pengembangannya (Studi Kasus Provinsi Sumatera Barat, Jawa Barat dan Nusa Tenggara Barat)
}

\author{
Sarjana Membangun Desa (SMD) Program Evaluation and Development Strategies \\ (Case Studies of West Sumatra, West Java and West Nusa Tenggara Province)
}

\author{
YELLY REFITA $^{1 *}$, HERMANTO SIREGAR ${ }^{1}$, ARIF IMAM SUROSO ${ }^{1}$ \\ ${ }^{1}$ Program Studi Ilmu Perencanaan Pembangunan Wilayah dan Perdesaan, Institut Pertanian Bogor, \\ Jl. Kamper Lingkar kampus, Level 5 Wing 2 Kampus IPB Darmaga, Bogor 16680; *Penulis korespondensi, \\ e-mail: yellykyu@gmail.com
}

(Diterima: 29 Agustus 2016; Disetujui: 10 Januari 2017)

\begin{abstract}
Sarjana Membangun Desa (SMD), or Bachelors Builds Villages, is a program that places undergraduate degree holders to empower livestock farmers which implemented by the Ministry of Agriculture Republic of Indonesia. This program has been started since 2007 with the number of beneficiaries has reached 2,694 groups scattered across Indonesia. This study aimed to conduct a thorough evaluation of the implementation of SMD, covering from the identification of potential region, evaluation of the effectiveness of the program and the formulation of the development strategies. The results showed that SMD has not been implemented based on the region potentials. The evaluation on the effectiveness of SMD on economic, technical and institutional indicators showed that the program has not been effective in achieving its goal. The CIPP (Context, Input, Process, and Product) evaluation showed that the causes of the ineffectiveness of the program are: (1) the program has no strategic plan; (2) lack of supports and participation from local government and communities; and (3) ineffectiveness at the selection and recruitment stage, reporting, monitoring and evaluation. Based on the result of Analytic Hierarchy Process (AHP) analysis, the strategy that needs to be put as priority to improve the effectiveness of the SMD is human resources strengthening which can be implemented through training and counseling.
\end{abstract}

Keywords: Analytic Hierarchy Process (AHP), CIPP Evaluation Method, Sarjana Membangun Desa

\begin{abstract}
ABSTRAK
Sarjana Membangun Desa (SMD) adalah program pemberdayaan peternak yang dilaksanakan oleh Direktorat Jenderal Peternakan dan Kesehatan Hewan, Kementerian Pertanian. Program ini telah dilaksanakan sejak tahun 2007, dengan jumlah penerima manfaat program sebanyak 2,694 kelompok yang tersebar di seluruh Indonesia. Penelitian ini bertujuan melakukan evaluasi menyeluruh terhadap pelaksanaan program SMD, mulai dari identifikasi potensi daerah, evaluasi efektivitas program hingga perumusan strategi pengembangan program. Hasil penelitian menunjukkan bahwa program SMD belum dilaksanakan berdasarkan potensi wilayah kelompok penerima. Hasil evaluasi efektivitas program SMD terhadap indikator ekonomi, indikator teknis dan indikator kelembagaan, menunjukkan bahwa program tersebut belum efektif dalam mencapai
\end{abstract}


tujuannya. Melalui evaluasi CIPP (Context, Input, Process, dan Product), diidentifikasi bahwa faktor penghambat ketidakefektifan program SMD adalah: (1) rencana strategis belum dibuat, (2) partisipasi para pemimpin pemerintahan dan masyarakat setempat masih rendah, dan (3) kurangnya efektivitas dalam proses seleksi (perekrutan), pelaporan, serta monitoring dan evaluasi program. Berdasarkan analisis Analytic Hierarchy Process (AHP), strategi prioritas utama untuk meningkatkan efektivitas program SMD adalah melalui penguatan sumber daya manusia. Strategi ini dapat dilakukan melalui pelatihan dan konseling.

Kata kunci: Analytic Hierarchy Process (AHP), metode evaluasi Context, Input, Process, Product (CIPP), Sarjana Membangun Desa (SMD)

\section{PENDAHULUAN}

Program Sarjana Membangun Desa (SMD) adalah program pemberdayaan peternak yang dilaksanakan oleh Direktorat Jenderal Peternakan dan Kesehatan Hewan (Ditjen PKH), Kementerian Pertanian. Program SMD merupakan suatu program pemberdayaan yang dilakukan dengan menempatkan para lulusan perguruan tinggi bidang peternakan dan kesehatan hewan di kelompok ternak guna mengatasi kendala rendahnya kualitas sumber daya manusis (SDM) peternakan di pedesaan melalui transfer ilmu pengetahuan dan teknologi dari perguruan tinggi dan lembaga penelitian. Keberadaan SMD di kelompok ternak berbekal ilmu dan teknologi, kreativitas serta wawasan agribisnis, diharapkan dapat berinteraksi dan bersinergi membangun kerjasama yang harmonis dengan mengelola agribisnis berbasis peternakan. Dengan mengintegrasikan kedua potensi tersebut diharapkan dapat memberikan kinerja usaha peternakan yang lebih optimal (Ditjen PKH, 2012).

Program SMD diharapkan dapat
mengatasi berbagai permasalahan
pembangunan peternakan seperti: (1) tenaga
kerja yang didominasi usia tua dan
berpendidikan rendah yakni di atas 60 tahun
dengan pendidikan di bawah SLTA (Kementan,
2014; Solahuddin, 2008), (2) skala usaha yang
masih kecil yakni 1 sampai 3 ekor per peternak
(Hadi dan Ilham, 2002), (3) aksesibilitas
peternak terhadap permodalan masih rendah,
(4) daya tawar (bargaining power) yang rendah
peternak.

Program SMD telah dilaksanakan sejak tahun 2007, dengan jumlah total penerima manfaat program sebanyak 2,694 kelompok sampai dengan tahun 2012. Total anggaran yang telah dikeluarkan oleh pemerintah sebesar Rp 778.82 Miliar. Pada tahun 2013 program SMD dihentikan sementara karena kebijakan Pemerintah untuk mengevaluasi kembali seluruh program yang memberikan modal kepada masyarakat. Program SMD kembali dilaksanakan pada tahun 2014 sampai 2015 dengan konsep yang berbeda dengan program SMD sebelumnya, ketika satu sarjana tidak lagi mendampingi satu kelompok ternak namun beberapa kelompok di suatu wilayah tertentu.

Evaluasi merupakan suatu penilaian terhadap kebijakan dalam ketepatan pencapaian tujuan sasaran dan program (Surya, 2012). Dengan evaluasi dapat diketahui bagian mana dari suatu program yang masih memiliki kekurangan dalam pelaksanaannya. Oleh sebab itu, penting untuk melakukan evaluasi terhadap program SMD ini, untuk melihat sejauh mana efektivitas pelaksanaan program. Tulisan ini merupakan sebuah evaluasi sumatif terhadap program SMD. Dalam evaluasi sumatif menurut Stufflebeam (2003) pertanyaan yang perlu dijawab adalah apakah program dilaksanakan sesuai dengan kebutuhan; apakah program telah dilaksanakan dengan perencanaan yang baik dan anggaran yang cukup; dan apakah program tersebut berhasil.

Pertanyaan yang akan dijawab melalui penelitian ini adalah: (1) apakah perencanaan program SMD sudah dilaksanakan berdasarkan 
potensi daerah penerimanya? (2) sejauh mana efektivitas program SMD dalam mencapai tujuannya? dan (3) bagaimana strategi pengembangan program SMD kedepannya?

Tujuan penelitian ini adalah untuk menganalisis kesesuaian potensi peternakan daerah penerima program SMD, mengevaluasi efektivitas program SMD dalam pencapaian tujuan dan sasarannya, dan merumuskan strategi pengembangan program SMD.

\section{METODOLOGI}

Penelitian dilaksanakan di Provinsi Sumatera Barat, Jawa Barat dan Nusa Tenggara Barat. Pemilihan lokasi dilakukan secara purposive ketika ketiga provinsi tersebut merupakan lima besar penerima manfaat program SMD terbanyak (Jawa Barat, Sumatera Barat, Jawa Tengah, Jawa Timur, dan NTB). Total penerima manfaat program SMD di ketiga provinsi sampel sebesar $33.63 \%$ dari total penerima manfaat SMD nasional.

Jenis data yang digunakan adalah data primer dan data sekunder. Data primer diperoleh melalui wawancara, pengamatan langsung di lapangan, dan pengisian daftar pertanyaan (kuesioner) oleh narasumber. Data sekunder dikumpulkan dari publikasi BPS, dokumen-dokumen perencanaan dan pelaporan program SMD, jurnal, buku-buku, studi kepustakaan dan publikasi penelitian-penelitian sebelumnya.

Narasumber dalam penelitian ini adalah: (1) Direktur Budidaya Ternak, Ditjen PKH, (2) Sekretaris Ditjen PKH, (3) Kasubdit Kelembagaan dan Usaha, Ditjen PKH, (4) Kepala Dinas Peternakan dan Kesehatan Hewan Provinsi Jawa Barat, Sumatera Barat dan Nusa Tenggara Barat, (5) Kepala Dinas Peternakan dan Kesehatan Hewan Kabupaten (Bandung, Garut, Bogor, Solok, Tanah Datar, Lima Puluh Kota, Lombok Barat, Lombok Tengah dan Lombok Timur), (6) Dosen Fakultas Peternakan Universitas Andalas, Institut Pertanian Bogor, Universitas Mataram, (7) Tokoh masyarakat pedesaan (tiga desa per kabupaten), (8) Ketua
Asosiasi SMD di tiga provinsi sampel, dan (9) Sarjana pendamping dan kelompok penerima program SMD komoditas sapi potong di tiga provinsi sampel. Kelompok SMD yang diobservasi adalah kelompok komoditas sapi potong, dengan pertimbangan bahwa $52 \%$ dari total kelompok SMD mengusahakan komoditas sapi potong.

\section{Metode Pengolahan Data}

\section{Analisis Deskriptif}

Menurut Sugiyono (2008) metode analisis deskriptif merupakan metode penelitian dengan cara mengumpulkan data-data sesuai dengan yang sebenarnya kemudian data tersebut disusun, diolah dan dianalisis untuk dapat memberikan gambaran mengenai masalah yang ada. Dalam penelitian ini metode deskriptif digunakan untuk mengetahui potensi peternakan daerah penerima program SMD dan mengevaluasi sejauh mana efektifitas program SMD.

\section{Analisis Deskriptif Terkait Potensi Peternakan Daerah Melalui Metode LQ dan SSA}

Metode Location Quotient (LQ) digunakan untuk mengetahui aktivitas ekonomi yang merupakan indikasi sektor basis dan nonbasis. Metode LQ merupakan perbandingan relatif antara kemampuan sektor yang sama pada wilayah yang lebih luas (Rustiadi et al., 2011).

Persamaan LQ adalah sebagai berikut:

$$
L Q_{i j}=\frac{\mathrm{X}_{\mathrm{ij}} / \mathrm{X}_{\mathrm{i}}}{\mathrm{X}_{\mathrm{j}} / \mathrm{X}_{\ldots}}
$$

Dimana:

$\mathrm{LQ}_{\mathrm{ij}}=$ indeks pemusatan aktivitas peternakan di kabupaten;

$X_{i j}=$ PDRB sub sektor peternakan kabupaten;

$\mathrm{X}_{\mathrm{i}}=$ total PDRB sektor pertanian kabupaten;

$\mathrm{X}_{\mathrm{j}}=$ total PDRB sub sektor peternakan provinsi;

$\mathrm{X} \ldots=$ total PDRB sektor pertanian provinsi;

Suatu aktivitas $\mathrm{j}$ dikatakan memusat di wilayah i jika $L Q_{i j}$ lebih besar dari 1. 
Shift Share Analysis (SSA) digunakan untuk melihat potensi pertumbuhan produksi sektoral dari suatu kawasan/wilayah.

Persamaan SSA adalah sebagai berikut:

$$
\text { (a) }
$$

$S S A=\left(\frac{X \cdot \cdot t 1}{X \cdot \cdot t 0}-1\right)+\left(\frac{X_{. j(t 1)}}{X_{. j(t 0)}}-\frac{X \cdot \cdot_{t 1}}{X \cdot \cdot_{t 0}}\right)+\left(\frac{X_{i j(t 1)}}{X_{i j(t 0)}}-\frac{X_{. j(t 1)}}{X_{. j(t 0)}}\right)$ Dimana:

(a) = komponen share;

(b) = komponen proportional shift;

(c) = komponen differential shift;

$\mathrm{X} . .=$ nilai total aktivitas dalam total wilayah;

$\mathrm{X}_{\mathrm{j}}=$ nilai total aktivitas tertentu dalam total wilayah;

$X_{\mathrm{ij}}=$ nilai aktivitas tertentu dalam unit wilayah tertentu;

$\mathrm{t}_{1}=$ titik tahun akhir;

$\mathrm{t}_{0}=$ titik tahun awal.

\section{Analisis Deskriptif Terkait Evaluasi Program Melalui Model Evaluasi CIPP}

Evaluasi efektivitas program SMD pada penelitian ini dilaksanakan dengan model evaluasi CIPP yang diperkenalkan oleh Daniel L Stufflebeam dari Ohio University. Sesuai dengan namanya, evaluasi CIPP terdiri atas empat elemen yaitu Context, Input, Process dan Product. Evaluasi ini merupakan evaluasi menyeluruh terhadap program SMD dimulai dari perencanaan hingga capaian output program

Model evaluasi Context, Input, Process dan Product (CIPP) merupakan suatu kerangka yang komprehensif untuk melakukan evaluasi formatif dan sumatif proyek, personil, produk, organisasi atau suatu sistem (Zhang et al., 2011). Model evaluasi ini menekankan "Learning by Doing" untuk mengidentifikasi koreksi sebuah proyek yang bermasalah. Stufflebeam (2003) menekankan bahwa prinsip yang paling mendasar dalam model evaluasi ini adalah "not to prove, but to improve".

Evaluasi konteks, input, proses dan produk pada model evaluasi CIFF diuraikan Stufflebeam (2013) sebagai berikut. Evaluasi konteks merupakan fokus institusi yang mengidentifikasi peluang dan menilai kebutuhan. Oleh karena itu dalam evaluasi konteks, hal yang harus dilakukan adalah memberikan gambaran dan rincian terhadap lingkungan, kebutuhan serta tujuan (goal).

Evaluasi input adalah evaluasi yang bertujuan menyediakan informasi untuk menentukan bagaimana menggunakan sumber daya yang tersedia dalam mencapai tujuan program.

Evaluasi proses diarahkan pada sejauhmana kegiatan yang direncanakan tersebut sudah dilaksanakan. Ketika suatu program sudah disetujui dan dimulai, maka kebutuhan evaluasi proses dalam menyediakan umpan balik (feedback) bagi orang yang bertanggungjawab dalam melaksanakan program tersebut.

Evaluasi produk merupakan bagian terakhir dari model CIPP. Evaluasi ini bertujuan mengukur dan menginterpretasikan capaiancapaian program. Evaluasi produk menunjukkan perubahan-perubahan yang terjadi pada input. Dalam proses evaluasi produk menyediakan informasi apakah program itu akan dilanjutkan, dimodifikasi, bahkan dihentikan.

\section{Analytic Hierarchy Process (AHP)}

Metode AHP digunakan untuk memodelkan strategi pengembangan program SMD, agar pelaksanaan program lebih efektif ke depannya, dengan menggunakan nilai komparasi berpasangan (pairwise comparison). AHP merupakan proses pengambilan keputusan multikriteria dengan beberapa faktor yang disusun dalam bentuk hirarki (Saaty, 1990).

\section{HASIL DAN PEMBAHASAN}

\section{Analisis Potensi Ekonomi Wilayah Terkait Potensi Peternakan Daerah Penerima Program SMD}

Pembangunan sektoral dan pembangunan wilayah harus berjalan selaras. Pembangunan sektoral tanpa berorientasi pembangunan wilayah akan menyebabkan tidak optimalnya pembangunan sektoral tersebut. Pembangunan wilayah tidak akan terwujud tanpa pembangunan sektoral. Oleh sebab itu, agar pengembangan sektor peternakan dapat berjalan 
efektif dan efisien, dipandang perlu dilakukan analisis potensi sub sektor peternakan, sehingga diharapkan dapat diidentifikasi daerah mana saja yang merupakan daerah basis peternakan.

Berdasarkan hasil analisis LQ dan SSA di Provinsi Sumatera Barat terdapat 11 kabupaten/kota yang merupakan daerah basis sub sektor peternakan $(64.71 \%)$, dan delapan kabupaten/kota yang sub sektor peternakannya memiliki keunggulan kompetitif. Di Provinsi Jawa Barat terdapat dua belas kabupaten/kota yang merupakan daerah basis sub sektor peternakan (54.55\%), dan 21 kabupaten/kota memiliki daya saing kompetitif (95.45\%). Sementara di Provinsi Nusa Tenggara Barat (NTB) terdapat empat kabupaten/kota yang merupakan daerah basis sub sektor $(40 \%)$ dan delapan kabupaten/kota merupakan daerah yang memiliki keunggulan kompetitif pada sub sektor peternakan $(80 \%)$. Penyebaran daerah basis dan berdaya saing kompetitif secara spasial disajikan pada Gambar 1.

Dari hasil perhitungan LQ dan SSA dapat disimpulkan bahwa program SMD belum dilaksanakan sesuai dengan potensi daerah penerimanya. Hal ini juga menyebabkan salah satu tujuan program SMD untuk pengembangan kawasan peternakan belum tercapai. Meskipun demikian, karena program SMD sudah dilaksanakan, maka analisis potensi wilayah ini akan digunakan sebagai basis penerapan program strategi peningkatan program SMD.

Program pengembangan kelompok SMD kedepan sebaiknya diterapkan berbeda pada daerah basis dan non basis, serta daerah yang memiliki keunggulan kompetitif dan yang tidak memiliki keunggulan kompetitif. Pada daerah yang merupakan basis sub sektor peternakan dan memiliki keunggulan kompetitif, ketika daerah tersebut telah dapat memenuhi permintaan dalam daerahnya dan telah melakukan ekspor ke daerah lain, kebijakan yang perlu diambil adalah terkonsentrasi pada sektor hilir (pemasaran). Daerah yang bukan basis dan tidak memiliki keunggulan kompetitif perbaikan sarana dan prasarana merupakan fokus utama.

\section{Evaluasi Efektivitas Program SMD}

\section{Evaluasi Konteks (Context Evaluation)}

Terdapat dua indikator yang dinilai pada evaluasi konteks, yaitu ketepatan pelaksanaan program SMD dibandingkan dengan permasalahan pembangunan peternakan, serta apakah program SMD telah memiliki rencana kerja strategis terkait dengan program. Esensi kebijakan publik adalah untuk memecahkan masalah yang tumbuh kembang di masyarakat.

Berdasarkan hasil wawancara dengan narasumber disimpulkan bahwa secara konteks program SMD telah menjawab berbagai permasalahan dalam pembangunan peternakan. Jawaban tersebut berupa pemberian modal, pendampingan oleh lulusan perguruan tinggi, dan pembinaan secara intensif kepada kelompok ternak. Sodiq (2010) menyatakan bahwa program SMD telah menciptakan lapangan kerja bagi tenaga kerja terdidik di pedesaan.

Indikator penilaian evaluasi konteks lainnya adalah adanya rencana kerja strategis terkait dengan program, minimal lima tahun, dilengkapi dengan rencana kerja program per tahun. Mikkelsen et al. (1987) menyatakan bahwa suatu proyek disebut berkesinambungan bila mampu menghasilkan tingkat manfaat yang tepat dalam jangka waktu yang lama setelah berakhirnya bantuan keuangan utama, bantua manajerial, dan teknik dari donor internal. Untuk mampu mewujudkan hal tersebut maka diperlukan suatu rencana kerja strategis minimal lima tahun. Program SMD tidak akan berhasil jika hanya berdasarkan program jangka pendek saja, sebab nilai strategis program tahunan sangat rendah.

Walaupun selama tahun 2007 sampai 2012 program SMD dilaksanakan setiap tahun, Ditjen PKH belum menyusun rencana strategis pelaksanaan program SMD. Dasar pelaksanaan program adalah Petunjuk Pelaksanaan yang disusun setiap tahun. Program SMD dilaksanakan setiap tahun namun belum berkesinambungan. Tidak ada proyeksi realitas dari tujuan program, jadwal waktu dan pentahapan program. 


\section{Evaluasi Input (Input Evaluation)}

Salah satu faktor yang menghambat atau memperlancar pelaksanaan suatu program adalah siapa dan berapa banyak unsur pelaksana program. Dalam evaluasi input dilakukan evaluasi terhadap peranan dan kinerja kelembagaan yang terlibat dalam program SMD.

Pelaksanaan program SMD sebagian besar dilaksanakan oleh pemerintah pusat (Ditjen $\mathrm{PKH}$ ), mulai dari perencanaan hingga evaluasi. Demikian juga dengan anggaran pelaksanaan program SMD, seluruh anggaran disediakan melalui Anggaran Pendapatan dan Belanja Negara (APBN). Belum ada dukungan anggaran dari Anggaran Pendapatan dan Belanja Daerah (APBD) dan Perguruan Tinggi. Anggaran yang hanya tersedia dari APBN, menyebabkan keterbatasan pelaksanaan program terutama pembinaan, monitoring dan evaluasi.

Melalui evaluasi input dapat dilihat bahwa pelaksanaan program SMD belum mengikuti azas "money follows function" yang dituangkan dalam Undang Undang (UU) Nomor 32 Tahun 2004 tentang Pemerintah Daerah dan UU Nomor 33 Tahun 2004 tentang Perimbangan Keuangan antara Pemerintah Pusat dan Pemerintah Daerah. Money Follows Function berarti besarnya distribusi keuangan didasarkan oleh distribusi kewenangan tugas dan tanggung jawab yang telah ditentukan terlebih dahulu (Mahi, 2001).

\section{Evaluasi Proses (Process Evaluation)}

Evaluasi proses terdiri atas evaluasi terhadap proses perencanaan, seleksi, pelaporan, monitoring dan evaluasi program SMD.

Proses perencanaan program SMD dilaksanakan secara top-down, artinya proses perencanaan hanya dilaksanakan oleh pemerintah pusat dalam hal ini Ditjen PKH. Menurut Clayton et al. (2000) penyebab dari kegagalan yang bersifat top-down adalah: (1) kegagalan menangkap isu yang berkembang di masyarakat, (2) kegagalan informasi akibat ketiadaan data atau tidak diperolehnya data secara memadai, (3) kegagalan menyatukan upaya dan sasaran dari berbagai aktivitas/ proyek yang ada, (4) kegagalan institusi yakni akibat tidak bekerjanya institusi yang ada secara memadai, serta (5) kegagalan mempersatukan visi seluruh stakeholders.

Philips et al. (2014) menyatakan bahwa penetapan kriteria sangat penting dilakukan agar tujuan program dapat tercapai. Kriteria penerima program SMD telah ditetapkan melalui Pedoman Pelaksanaan Program SMD yang terdiri atas kriteria sarjana pendamping dan kriteria kelompok ternak. Meskipun demikian di lapangan masih ditemukan penerimaan program yang tidak sesuai kriteria yang ditentukan, yaitu kriteria untuk kelompok ternak. Dalam pedoman pelaksanaan program SMD disebutkan bahwa kriteria kelompok ternak binaan SMD adalah kelompok yang sudah ada dan aktif, dapat dipercaya serta mampu mengembangkan usaha melalui kerjasama kelompok, namun fakta di lapangan masih terdapat kelompok penerima program SMD yang masih baru atau baru dibentuk saat mengikuti seleksi program SMD.

Form laporan yang terdapat pada petunjuk pelaksanaan program SMD dinilai masih belum efektif. Format tersebut hanya berisi perkembangan kelompok, perkembangan populasi ternak yang dimiliki kelompok, serta jumlah penjualan ternak dan keuntungan yang didapat oleh kelompok. Dalam format tersebut tidak disampaikan kendala apa saja yang dihadapi oleh kelompok.

Monitoring dan evaluasi program SMD dimaksudkan untuk mengetahui dengan pasti pencapaian hasil, kemajuan, kendala dan pelaksanaan penguatan kelembagaan ekonomi peternak sehingga dapat dinilai dan dipelajari untuk perbaikan pelaksanaan rencana di masa yang akan datang. Monitoring dan evaluasi dilaksanakan oleh Ditjen PKH dan dinas provinsi. Dinas kabupaten/kota tidak melaksanakan evaluasi secara khusus karena tidak tersedianya anggaran monitoring dan evaluasi di dinas kabupaten/kota. 

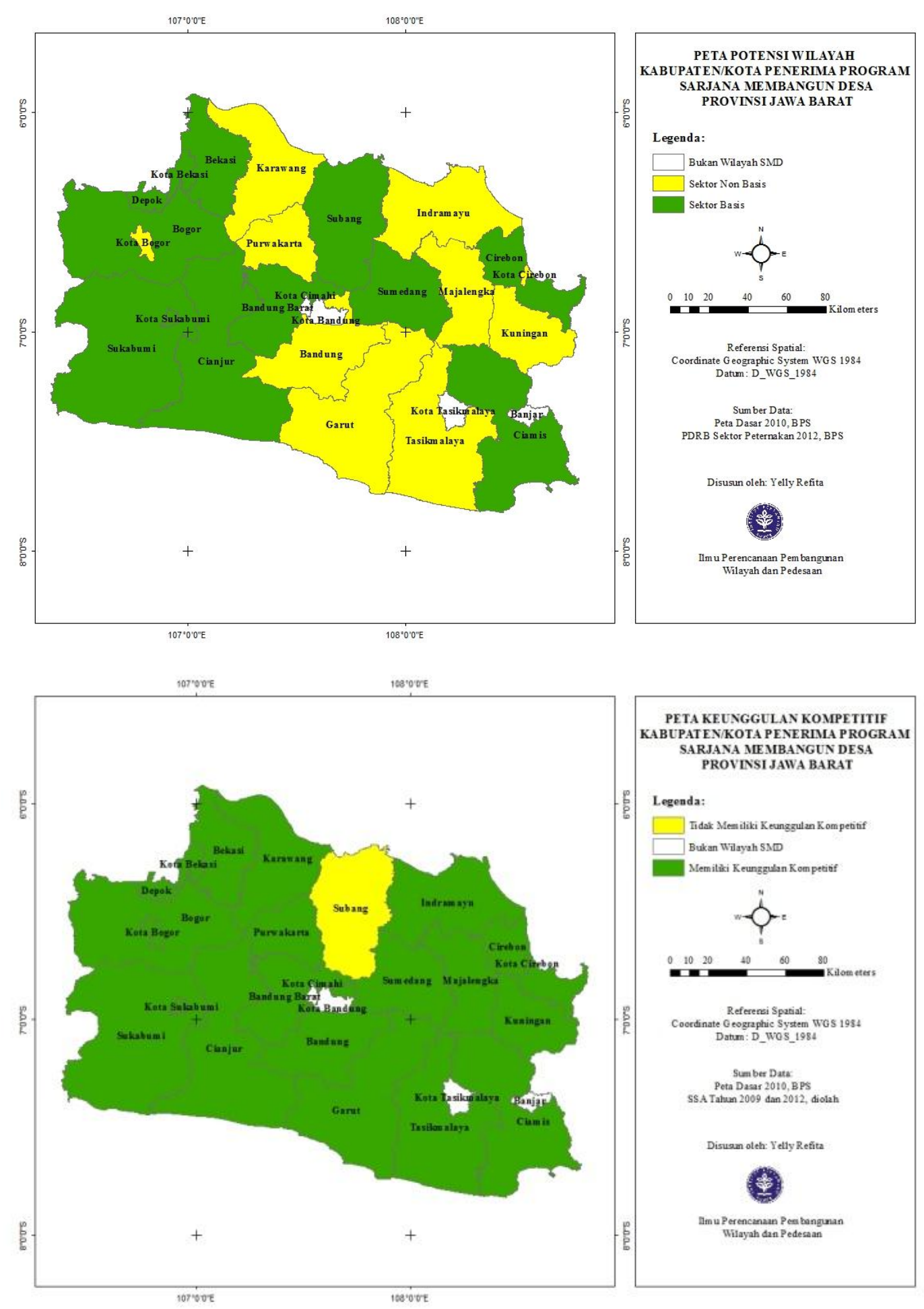

Gambar 1. Peta daerah basis dan berdaya saing kompetitif di Jawa Barat Sumber data: Peta dasar BPS (2010); PDRB sektor pertanian dan sub sektor peternakan BPS (2012). 

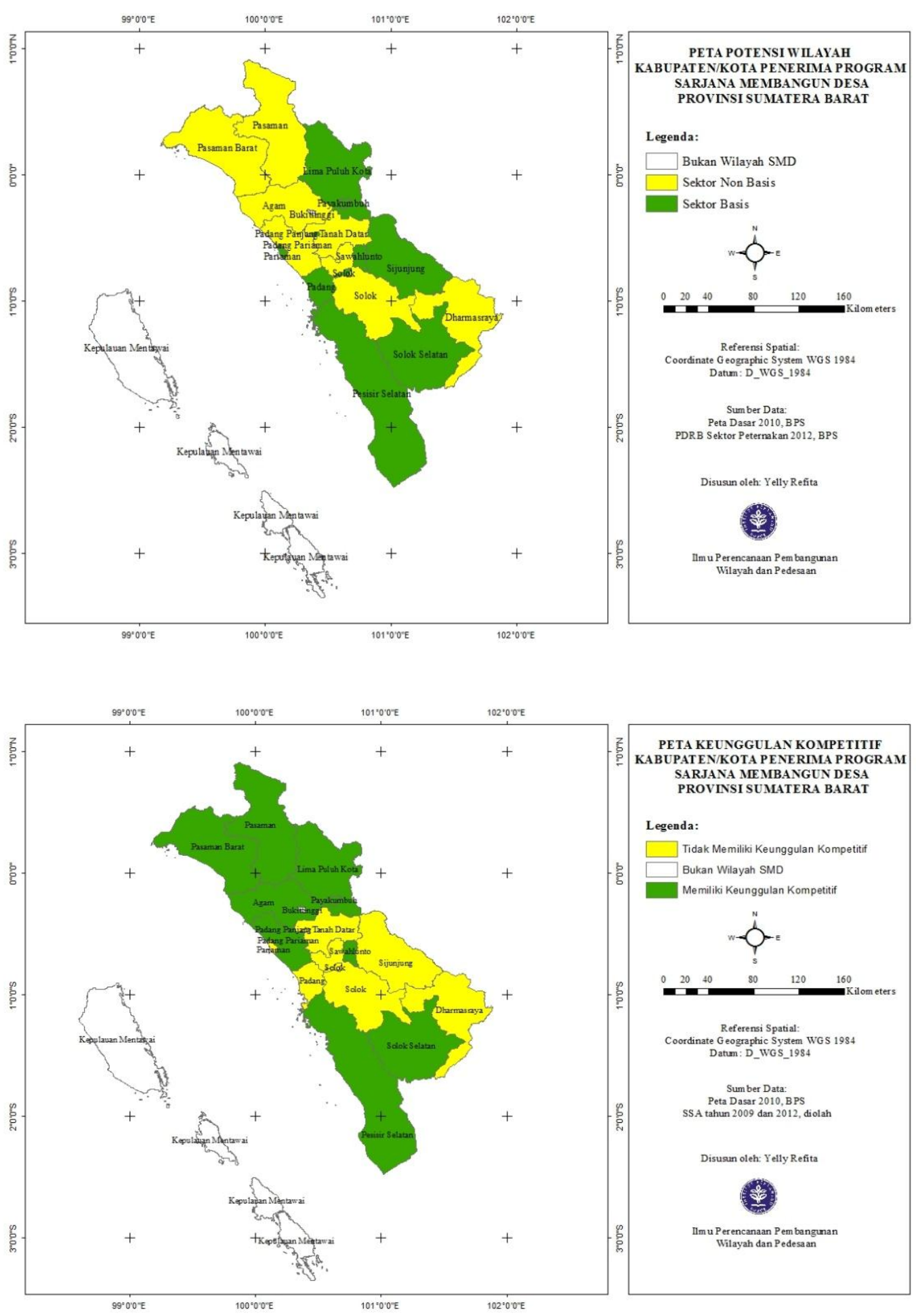

Gambar 2. Peta daerah basis dan berdaya saing kompetitif di Provinsi Sumatera Barat Sumber data: Peta dasar BPS (2010); PDRB sektor pertanian dan sub sektor peternakan BPS (2012). 

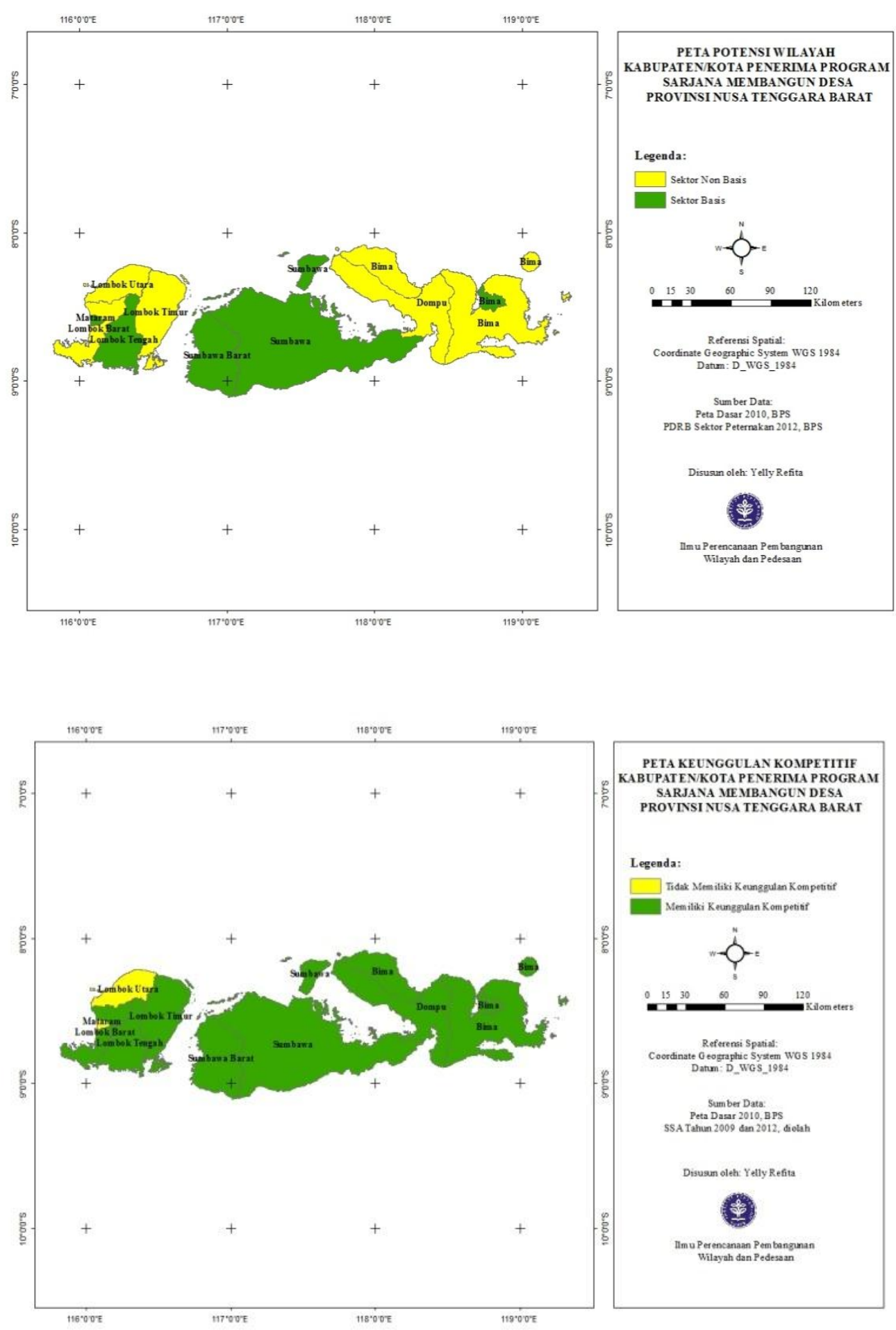

Gambar 3. Peta daerah basis dan berdaya saing kompetitif di Provinsi NTB Sumber data: Peta dasar BPS (2010); PDRB sektor pertanian dan sub sektor peternakan BPS (2012). 


\section{Evaluasi Produk (Product Evaluation)}

Evaluasi produk dilakukan dengan menilai capaian tujuan program SMD. Capaian tujuan program SMD dalam petunjuk pelaksanaan diukur melalui capaian tiga indikator yaitu: indikator ekonomis, indikator teknis, dan indikator kelembagaan. Indikator ekonomis diukur dengan perkembangan asset kelompok SMD dan diversifikasi usaha kelompok SMD. Indikator teknis diukur melalui peningkatan populasi ternak kelompok SMD dan penerapan teknologi, sedangkan indikator kelembagaan diukur melalui meningkatnya status kelas kelompok, berkembangnya kelembagaan usaha dan kelompok ternak sebagai tempat magang/pelatihan bagi masyarakat.

\section{Capaian Indikator Ekonomi}

Dalam kurun waktu tahun 2010 sampai 2012 kelompok SMD komoditas sapi potong di Provinsi Sumatera Barat mengalami penurunan aset rata-rata $7 \%$ per tahun. Sementara kelompok SMD komoditas sapi potong di Provinsi Jawa Barat dan NTB mengalami peningkatan masing-masing $0.07 \%$ dan $19.2 \%$. Perkembangan asset kelompok SMD Provinsi Sumatera Barat, Jawa Barat dan NTB disajikan pada Tabel 1.

Tabel 1. Perkembangan data aset kelompok SMD komoditas sapi potong Provinsi Sumatera Barat, Jawa Barat dan Nusa Tenggara Barat tahun 2010 sampai 2012

\begin{tabular}{|c|c|c|c|c|c|c|c|}
\hline No & Provinsi/Tahun & $\begin{array}{c}\text { Aset Awal (RUK) } \\
\text { (Rp) }\end{array}$ & $\begin{array}{l}\text { Aset Saat Ini } \\
\text { (Rp) }\end{array}$ & $\begin{array}{c}\text { Peningkatan } \\
(\%)\end{array}$ & $\begin{array}{l}\text { Rata-rata } \\
\text { perbedaan }\end{array}$ & t- hitung & t-tabel \\
\hline \multirow[t]{4}{*}{1} & Sumatera Barat & & & & $-1,063,114,109$ & -0.000 & 3.185 \\
\hline & 2010 & $6,375,000,000$ & $6,167,060,366$ & -3.26 & & & \\
\hline & 2011 & $6,952,000,000$ & $6,458,461,000$ & -7.09 & & & \\
\hline & 2012 & $3,075,000,000$ & $2,713,364,525$ & -11.76 & & & \\
\hline \multirow[t]{4}{*}{2} & Jawa Barat & & & & $-1,507,364,893$ & -1.000 & 3.185 \\
\hline & 2010 & $1,447,500,000$ & $1,474,200,262$ & 1.84 & & & \\
\hline & 2011 & $2,888,000,000$ & $3,215,004,201$ & 11.32 & & & \\
\hline & 2012 & $15,090,000,000$ & $13,228,930,644$ & -12.33 & & & \\
\hline \multirow[t]{4}{*}{3} & Nusa Tenggara Barat & & & & & & \\
\hline & 2010 & $3,575,000,000$ & $5,000,633,541$ & 39.87 & $2,790,208,383$ & 2.365 & 3.185 \\
\hline & 2011 & $4,551,000,000$ & $5,762,117,670$ & 26.61 & & & \\
\hline & 2012 & $1,250,000,000$ & $1,403,457,172$ & 12.27 & & & \\
\hline
\end{tabular}

Sumber: Ditjen PKH (2013).

Diversifikasi usaha yang dilakukan oleh kelompok SMD adalah penjualan pupuk kompos dan pemasaran daging.

Berdasarkan hasil uji nyata dengan selang kepercayaan 95\%, dapat diketahui bahwa $\mathrm{t}$-hitung $<\mathrm{t}$ - tabel yang berarti belum terlihat perbedaan rata-rata jumlah aset sebelum dan sesudah menerima program SMD dalam sela waktu tahun 2010 sampai 2012. Hal ini berarti program SMD belum efektif dalam mencapai tujuannya meningkatkan pendapatan peternak.

\section{Capaian Indikator Teknis}

Pada tahun 2010 sampai 2012 populasi sapi potong kelompok SMD di Provinsi Sumatera Barat selalu mengalami penurunan.
Persentase penurunannya selalu meningkat setiap tahun, ketika pada tahun 2010 penurunan populasi sapi Provinsi Sumatera Barat sebesar $10.04 \%$, meningkat menjadi $12.01 \%$ pada tahun 2011, kemudian meningkat lagi menjadi 23.38\%. Pada tahun 2010 populasi sapi kelompok ternak di provinsi Jawa Barat meningkat sebesar 2\%, namun kemudian menurun pada tahun 2011 dan 2012 sebesar $23.35 \%$ dan $21.90 \%$. Sementara di Provinsi NTB populasi sapi potong kelompok SMD selalu meningkat setiap tahunnya. Rata-rata peningkatan populasi sapi potong kelompok SMD tahun 2010 sampai 2012 adalah $19.35 \%$.

Peningkatan terbesar terjadi pada tahun 2011 sebesar 25.95\%. Selengkapnya capaian 
populasi sapi potong kelompok SMD disajikan pada Tabel 2.

Sementara penerapan teknologi budidaya yang diterapkan oleh Kelompok SMD di Provinsi Sumatera Barat, Jawa Barat, dan NTB adalah pengolahan pakan ternak, pengolahan pupuk, penerapan Inseminasi Buatan (IB), dan biogas. Berdasarkan hasil uji nyata dengan selang kepercayaan 95\%, dapat diketahui bahwa $t$-hitung $<\mathrm{t}$ - tabel yang berarti belum terlihat perbedaan rata-rata populasi sebelum dan sesudah menerima program SMD dalam sela waktu tahun 2010 sampai 2012. Hal ini berarti program SMD belum efektif dalam mencapai tujuannya meningkatkan populasi ternak.

Tabel 2. Perkembangan Populasi Sapi Potong Kelompok SMD Provinsi Sumatera Barat, Jawa Barat dan NTB Tahun 2010-2012

\begin{tabular}{llrrrrrr}
\hline No & Provinsi/Tahun & $\begin{array}{c}\text { Populasi Awal } \\
\text { (RUK) (Ekor) }\end{array}$ & $\begin{array}{c}\text { Populasi Saat } \\
\text { Ini (Ekor) }\end{array}$ & $\begin{array}{c}\text { Peningkatan } \\
(\%)\end{array}$ & $\begin{array}{c}\text { Rata-rata } \\
\text { perbedaan }\end{array}$ & t- hitung & t-tabel \\
\hline 1 & Sumatera Barat & & & & 190 & 0.282 & 3.185 \\
& 2010 & 498 & 448 & -10.04 & & & \\
& 716 & 630 & -12.01 & & & \\
& 2011 & 231 & 177 & -23.38 & & & 3.185 \\
& Jawa Barat & & & & 127 & 0.040 & \\
& 2010 & 100 & 102 & 2.00 & & & \\
2011 & 197 & 151 & -23.35 & & & \\
& 2012 & 379 & 296 & -21.90 & & -0.046 & 3.185 \\
\hline 3 & Nusa Tenggara Barat & & & & -210 & & \\
& 2010 & 525 & 604 & 15.05 & & & \\
& 2011 & 474 & 590 & 25.95 & & & \\
& 2012 & 88 & 103 & 17.05 & & & \\
\hline
\end{tabular}

Sumber: Ditjen PKH (2013).

\section{Capaian Indikator Kelembagaan}

Pengembangan kelembagaan peternak diarahkan pada upaya pembentukan badan usaha yang komersial sehingga berorientasi ekonomi dan mampu meningkatkan daya saing dan nilai tambah produk yang dihasilkan (Sodiq et al., 2014). Ukuran keberhasilan indikator kelembagaan adalah meningkatnya status kelompok ternak menjadi koperasi dan badan usaha serta kelompok tersebut telah menjadi Pusat Pelatihan Pertanian Pedesaan Swadaya (P4S) sebagai tempat magang/ pelatihan kelompok ternak lainnya. Di Provinsi Sumatera Barat terdapat lima kelompok ternak yang telah berstatus koperasi dan badan usaha lainnya, sementara di Provinsi Jawa Barat ada empat kelompok yang telah meningkatkan status kelompoknya, dan Provinsi NTB hanya satu kelompok yang menjadi badan usaha. Untuk kelompok yang telah menjadi P4S, Provinsi Sumatera Barat lima kelompok, Jawa Barat dua kelompok, sementara NTB belum ada kelompok yang diusulkan menjadi P4S.

\section{Perumusan Strategi Peningkatan}

\section{Efektivitas Program SMD}

Pengolahan AHP dilakukan dengan menggunakan Expert Choice 1.1. Jumlah kuesioner yang diolah sebanyak 23 kuesioner, dengan nilai konsistensi 0.08. Pengolahan AHP dilakukan secara horizontal dan vertikal.

Hasil pengolahan AHP secara horizontal pada level alternatif strategi. Strategi penguatan sumberdaya manusia SMD dan kelompok ternak memiliki nilai bobot 0.300 , strategi penguatan kelembagaan kelompok ternak memiliki nilai bobot 0.251 , strategi penguatan permintaan dan akses pasar memiliki nilai bobot 0.192 , dan strategi penerapan teknologi dan peningkatan produktivitas memiliki nilai bobot 0.257 [Gambar 4]. Dengan demikian urutan strategi peningkatan efektivitas program SMD adalah melalui peningkatan sumberdaya manusia SMD dan kelompok ternak, kemudian penerapan teknologi dan peningkatan produktivitas, berikutnya penguatan 
kelembagaan kelompok ternak, dan terakhir penguatan permintaan dan akses pasar. Selanjutnya pada masing-masing strategi dilakukan pengolahan AHP secara vertikal untuk masing-masing strategi.

\section{Strategi Penguatan Sumber Daya Manusia SMD dan Kelompok Ternak}

Salah satu karakteristik SDM pertanian di Indonesia adalah tingkat pendidikan yang masih relatif rendah. Rendahnya kualitas tenaga kerja menurut Solahuddin (2008) menyebabkan rendahnya efisiensi usaha tani di pedesaan. Tantangannya adalah bagaimana mempersiapkan SDM pertanian agar mampu menerapkan teknologi pertanian dalam kegiatan usahataninya. Pengembangan SDM pertanian tidak hanya dilakukan untuk meningkatkan kemampuan dalam menerapkan teknologi, tetapi juga meningkatkan motivasi dan persepsi tentang pertanian modern, perbaikan moral, serta transformasi tradisi dan kultur menjadi pertanian berbudaya industri.

Dalam strategi penguatan sumberdaya manusia SMD dan kelompok ternak, faktor yang paling berpengaruh adalah potensi sumberdaya manusia peternakan, sedangkan aktor utama dalam penerapan strategi ini adalah SMD dan kelompok ternak. Pengolahan vertikal pada level strategi disajikan pada Tabel 3.

Tabel 3. Pengolahan vertikal pada level strategi

\begin{tabular}{|c|c|c|c|c|}
\hline Strategi & Aktor & Nilai & Faktor & Nilai \\
\hline \multirow{5}{*}{$\begin{array}{l}\text { Penguatan } \\
\text { sumberdaya } \\
\text { manusia SMD } \\
\text { dan kelompok } \\
\text { ternaknya }\end{array}$} & SMD dan kelompok ternak & 0.351 & Potensi SDM peternakan & 0.322 \\
\hline & Pemerintah pusat & 0.188 & $\begin{array}{l}\text { Tingkat konsumsi produk } \\
\text { peternakan }\end{array}$ & 0.121 \\
\hline & Pemerintah daerah & 0.149 & Potensi sumberdaya peternakan & 0.238 \\
\hline & Perguruan tinggi & 0.172 & Impor produk peternakan & 0.114 \\
\hline & Tokoh masyarakat & 0.140 & Institusi pembiayaan & 0.205 \\
\hline \multirow{5}{*}{$\begin{array}{l}\text { Penguatan } \\
\text { kelembagaan } \\
\text { kelompok ternak }\end{array}$} & SMD dan kelompok ternak & 0.166 & Potensi SDM peternakan & 0.249 \\
\hline & Pemerintah pusat & 0.232 & $\begin{array}{l}\text { Tingkat konsumsi produk } \\
\text { peternakan }\end{array}$ & 0.169 \\
\hline & Pemerintah daerah & 0.296 & Potensi sumberdaya peternakan & 0.242 \\
\hline & Perguruan tinggi & 0.109 & Impor produk peternakan & 0.117 \\
\hline & Tokoh masyarakat & 0.197 & Institusi pembiayaan & 0.223 \\
\hline \multirow{5}{*}{$\begin{array}{l}\text { Penguatan } \\
\text { permintaan dan } \\
\text { akses pasar }\end{array}$} & SMD dan kelompok ternak & 0.127 & Potensi SDM peternakan & 0.159 \\
\hline & Pemerintah pusat & 0.227 & $\begin{array}{l}\text { Tingkat konsumsi produk } \\
\text { peternakan }\end{array}$ & 0.149 \\
\hline & Pemerintah daerah & 0.328 & Potensi sumberdaya peternakan & 0.137 \\
\hline & Perguruan tinggi & 0.158 & Impor produk peternakan & 0.351 \\
\hline & Tokoh masyarakat & 0.160 & Institusi pembiayaan & 0.204 \\
\hline \multirow{5}{*}{$\begin{array}{l}\text { Penerapan } \\
\text { teknologi dan } \\
\text { peningkatan } \\
\text { produktivitas }\end{array}$} & SMD dan kelompok ternak & 0.298 & Potensi SDM peternakan & 0.399 \\
\hline & Pemerintah pusat & 0.112 & $\begin{array}{l}\text { Tingkat konsumsi produk } \\
\text { peternakan }\end{array}$ & 0.195 \\
\hline & Pemerintah daerah & 0.205 & Potensi sumberdaya peternakan & 0.165 \\
\hline & Perguruan tinggi & 0.283 & Impor produk peternakan & 0.101 \\
\hline & Tokoh masyarakat & 0.102 & Institusi pembiayaan & 0.140 \\
\hline
\end{tabular}

Sumber: Hasil analisis, 2016. 


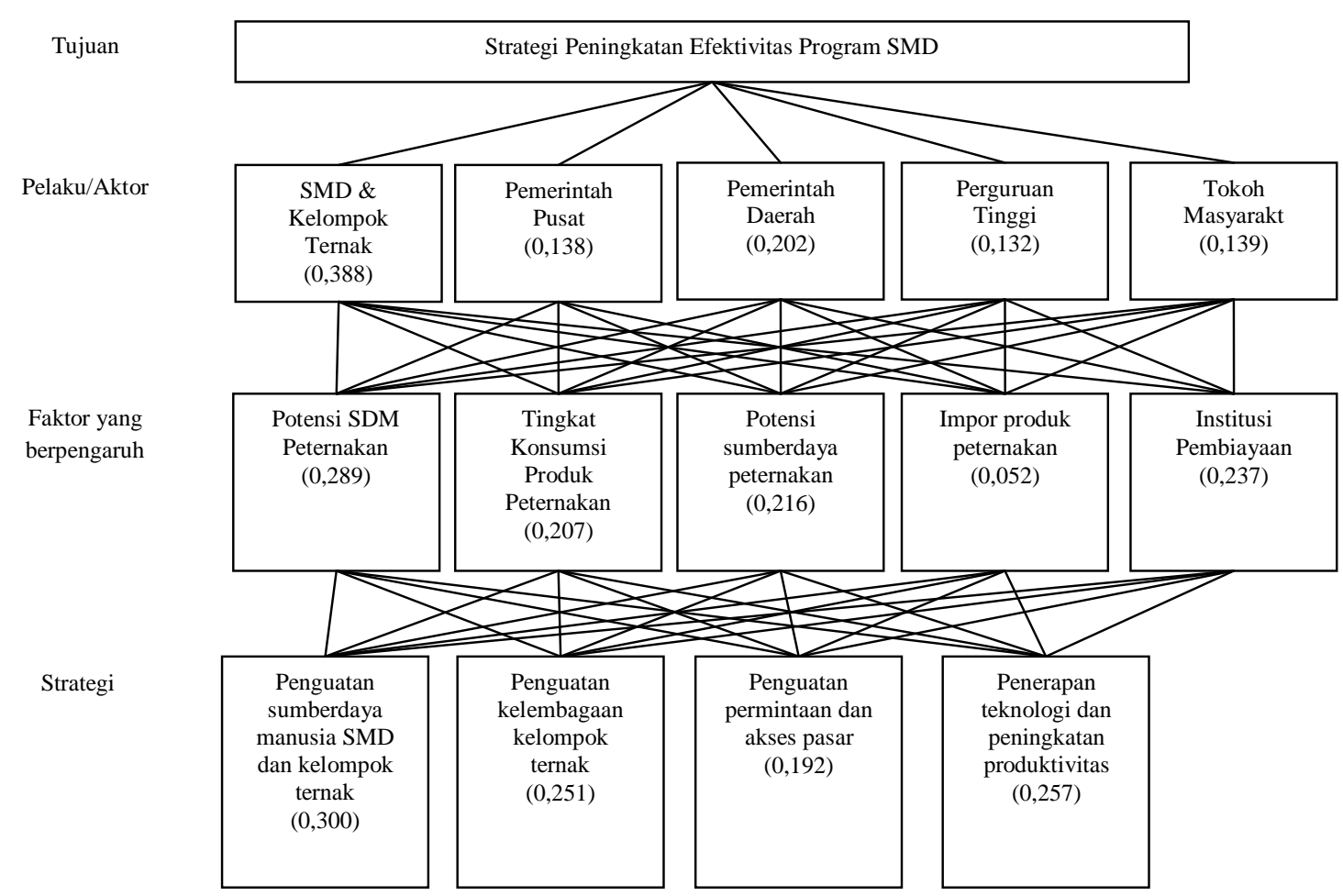

Gambar 4. Hirarki strategi peningkatan efektivitas program SMD Sumber: Hasil analisis, 2016.

\section{Strategi Penguatan Kelembagaan}

\section{Kelompok Ternak}

Setiap upaya dan strategi pemberdayaan kelembagaan petani memiliki keterkaitan kuat dengan kondisi sosio-teknis komunitas petani (Suradisastra, 2008). Penerapan kebijakan pemberdayaan memerlukan strategi pendekatan yang mampu memfasilitasi aspirasi sosialbudaya dan aspirasi teknis petani dan kelembagaan petani serta lembaga pembangunan pertanian setempat. Data AHP menunjukkan bahwa aktor utama dalam strategi penguatan kelembagaan kelompok ternak adalah pemerintah daerah. Permasalahan mendasar yang melatarbelakangi pentingnya transformasi kelembagaan meliputi struktur kelembagaan tidak lengkap, status badan hukum masih bersifat informal, pembagian tugas (job description) yang belum jelas, sistem koordinasi belum efektif, serta jenis kegiatan usaha belum mengikuti sistem dan usaha agribisnis (Saptana et al., 2013). Pemerintah daerah sebagai tim teknis yang mendampingi kelompok diharapkan mampu mengatasi permasalahan dalam transformasi kelembagaan kelompok ternak, melalui pendampingan dan penyuluhan yang berkelanjutan. Faktor yang paling berpengaruh dalam penerapan strategi penguatan kelembagaan kelompok ternak adalah potensi sumberdaya manusia peternakan.

\section{Strategi Penguatan Permintaan Pasar}

Faktor yang berpengaruh dalam strategi penguatan permintaan pasar adalah impor produk peternakan, sedangkan aktor utama dalam penerapan strategi ini adalah pemerintah pusat. Pemerintah pusat diharapkan mampu mengendalikan dan mengatur impor produk peternakan agar produk lokal dapat bersaing di pasar.

\section{Strategi Penerapan Teknologi dan Peningkatan Produktivitas}

Faktor yang berpengaruh dalam strategi penerapan teknologi dan peningkatan produktivitas adalah potensi sumberdaya peternakan, dengan aktor utama SMD dan kelompok ternaknya. Menurut Nuryanti et al. (2011) aspek sumberdaya manusia kelompok 
tani (kelompok ternak) sangat berperan dalam mengoptimalkan peran kelompok sebagai pelaku alih teknologi dan inovasi. SMD sebagai sarjana pendamping kelompok berperan penting dalam mengubah mindset anggota kelompok dalam menerima teknologi baru. SMD perlu meningkatkan kemampuan berkomunikasi dengan kelompok ternaknya. Aktor utama kedua adalah perguruan tinggi. Perguruan tinggi sebagai sumber informasi dan teknologi terbaru diharapkan mampu menghasilkan informasi dan teknologi yang mudah diadopsi oleh peternak. Berbagai hasil penelitian menunjukkan bahwa banyak introduksi teknologi mengalami kegagalan, dalam arti penerapan teknologi oleh masyarakat belum sesuai dengan yang diharapkan. Hal ini antara lain disebabkan teknologi yang dikembangkan seringkali tidak sesuai dengan kebutuhan penggunanya (Padmaningrum, 2008).

Hasil pengolahan pada level alternatif strategi diketahui bahwa strategi yang merupakan prioritas utama dalam meningkatkan efektivitas program SMD adalah melalui penguatan sumber daya manusia SMD dan kelompok ternak. Strategi ini dapat dilakukan melalui pelatihan dan penyuluhan dalam upaya peningkatan pengetahuan SMD dan peternak.

Dari hasil pengolahan AHP terhadap strategi peningkatan efektivitas program SMD, dapat disimpulkan bahwa keberhasilan program SMD tidak dapat diukur dalam waktu satu atau dua tahun saja. Perlu proses yang panjang agar program SMD dapat mencapai tujuan yang diinginkan. Oleh sebab itu, pemerintah sebaiknya melaksanakan peningkatan efektivitas program SMD secara kontinu. Pemberian modal saja tidak cukup jika dibandingkan dengan tujuan yang harus dicapai oleh SMD. Hal pertama yang harus dilakukan oleh pemerintah adalah meningkatkan kualitas sumber daya manusia SMD dan kelompok. Transfer ilmu pengetahuan dan teknologi serta penyuluhan merupakan serangkaian kegiatan yang dapat dilakukan untuk peningkatan sumberdaya manusia SMD dan kelompok ternak. Jika sumber daya manusia SMD dan kelompok ternak sudah baik maka peningkatan kelembagaan kelompok ternak akan lebih mudah dicapai.

\section{KESIMPULAN DAN REKOMENDASI}

\section{Kesimpulan}

Berdasarkan hasil penelitian dapat disimpulkan beberapa hal sebagai berikut: Pertama program SMD belum dilaksanakan sesuai dengan potensi daerah penerimanya, Kedua Program SMD belum efektif dalam pencapaian tujuannya. Beberapa faktor penghambat adalah program SMD belum memiliki rencana kerja strategis, pemerintah pusat peran lembaga lain masih kurang terutama dalam proses seleksi dan pendampingan, anggaran pendampingan tidak tersedia di dinas kabupaten/kota dan perguruan tinggi, tokoh masyarakat belum dilibatkan dalam pelaksanaan program SMD, perencanaan bersifat top-down, belum efektifnya proses pelaporan, monitoring dan evaluasi. Ketiga berdasarkan AHP, strategi yang merupakan prioritas utama dalam peningkatan efektivitas program SMD adalah melalui penguatan sumber daya manusia SMD dan kelompok ternak. Strategi ini dapat dilakukan melalui pelatihan dan penyuluhan.

\section{Rekomendasi}

Beberapa rekomendasi dari penelitian ini adalah diuraikan sebagai berikut. Pertama, dalam melaksanakan suatu program, Ditjen PKH terlebih perlu dahulu melakukan kajian terhadap kesesuaian program dengan potensi daerah penerima program dan kebutuhan daerah penerima program. Tujuan pemerintah untuk mengembangkan kawasan peternakan harus diiringi dengan penempatan program yang sesuai dengan potensi dan kebutuhan daerah. Kedua, perlu keberlanjutan program SMD, terutama untuk kelompok SMD yang masih berjalan dengan cara meningkatkan sumber daya manusia SMD dan kelompoknya melalui pelatihan di bidang keorganisasian/ 
kelembagaan, keuangan, pemasaran hasil, dan kewirausahaan. Kerjasama dengan penyuluh pertanian di lapangan perlu ditingkatkan terutama dalam hal pendekatan sosial-budaya yang dapat merangsang perubahan sikap, perilaku dan pola kerja SMD dan kelompok ternaknya. Pelaksanaan penyuluhan sebaiknya disesuaikan dengan potensi dan kebutuhan masing-masing daerah. Bagi daerah yang memiliki keunggulan komparatif dan kompetitif pada sub sektor peternakan, penyuluhan dan pelatihan yang diberikan difokuskan pada sektor hilir atau pemasaran, sedangkan daerah yang tidak memiliki keunggulan komparatif dan kompetitif penyuluhan dan pelatihan difokuskan pada sektor hulu. Ketiga, dana APBN merupakan stimulan dalam pembangunan peternakan. Penguatan asosiasi SMD yang merupakan asosiasi peternak lokal perlu dilakukan pemerintah untuk membantu pemerintah dalam menyukseskan program-program pemerintah. Keempat, keterlibatan pemerintah daerah perlu ditingkatkan, karena pemerintah daerah yang paling dekat dengan kelompok, sehingga dapat lebih mengetahui kelebihan dan kekurangan kelompok ternak penerima program. Ditjen PKH diharapkan dapat berbagi tugas dengan pemerintah daerah. Pemerintah daerah juga diharapkan dapat memberikan dukungan anggaran melalui APBD terhadap programprogram pemerintah pusat. Kelima, perlu penelitian lanjutan terhadap peran sarjana pendamping Program SMD dalam mengembangkan modal sosial di pedesaan, agar program SMD dapat adaptif dengan kondisi ekonomi pedesaan, sehingga memberikan manfaat terhadap kelompok ternak dan perekonomian pedesaannya. Selain itu diperlukan penelitian lebih lanjut terhadap potensi teknis peternakan di kabupaten/kota penerima program SMD, dengan memasukkan data ketersediaan pakan dan sarana prasarana peternakan.

\section{DAFTAR PUSTAKA}

Clayton, B. D., Dent, D., \& Dubois, D. (2000). Rural Planning in the Developing World with a Special Focus on Natural Resources:Lessons Learned and Potential Contributions to Sustainable Livelihoods An Overview. A Report to the UK Department for International Development.

Direktorat Jenderal Peternakan dan Kesehatan Hewan, Kementerian Pertanian. (2012). Pedoman Program Sarjana Membangun Desa Tahun 2012. Jakarta: Kementerian Pertanian.

Hadi, P. U., \& Ilham, N. (2002). Problem dan Prospek Pengembangan Usaha Pembibitan Sapi Potong di Indonesia. Jurnal Litbang Pertanian, 21 (4): 148-157.

Pusat Data dan Informasi Pertanian, Kementerian Pertanian. (2014). Statistik Tenaga Kerja Sektor Pertanian Tahun 2014. Pusat Data dan Informasi Pertanian. Jakarta: Kementerian Pertanian.

Mahi, B. R. (2001). Fiscal Decentralization: Its Impact On Cities Growth. Jurnal Ekonomi dan Pembangunan Indonesia FEUI, 2 (1), 120.

Mikkelsen, B., \& Narayan, D. (1993). Participation Evaluation. Washington, DC: World Bank.

Nuryanti. S., \& Swastika, D. K. S. (2011). Peran Kelompok Tani dalam Penerapan Teknologi Pertanian. Forum Penelitian Agro Ekonomi, 29 (2), 115-128.

Padmaningrum, D. (2008). Strategi Komunikasi dalam Mengantisipasi dan Memecahkan Kegagalan Penerapan Teknologi oleh Petani. Agritexts, 23 (2), 48-57

Philips, D., Waddington, H., \& With, H. (2014). Better Targeting of Farmers as A Channel for Poverty Reduction: A Systematic Revieu of Farmer Field Schools Targeting. Development Studies Research, 1 (1), 113136

Rustiadi, E.. Saefulhakim, S., \& Panuju, D. R. (2011). Perencanaan dan Pengembangan Wilayah. Bogor: Crestpent Press dan Yayasan Pustaka Obor Indonesia.

Saaty, T. L. (1990). How To Make a Decision: The Analytic Hierarchy Proses. European Journal of Operational Research, 48, 9-26. 
Saptana, Wahyuni, S., \& Pasaribu, S. M. (2013). Strategi Percepatan Transformasi Kelembagaan Gapoktan dan Lembaga Keuangan Mikro Agribisnis dalam Memperkuat Ekonomi di Perdesaan. Jurnal Manajemen\&Agribisnis, 10 (1), 60-70.

Solahudin, S. (2008). Pembangunan Pertanian Tangguh dan Berkelanjutan. Pemikiran Guru Besar Institut Pertanian Bogor, Perspektif Ilmu-Ilmu Pertanian dalam Pembangunan Nasional. Bogor.

Sodiq, A. (2010). Evaluasi Kinerja SMD dalam Program Percepatan Pencapaian Swasembada Daging Sapi (P2SDS) di Provinsi Jawa Tengah. Jurnal Ilmiah Inkoma, 21 (3),119-128

Sodiq, A., \& Hidayat, N. (2014). Kinerja dan Perbaikan Sistem Produksi Peternakan Sapi Potong Berbasis Kelompok di Pedesaan. Agripet, 14 (1), 56-64

Suradisastra, K. (2008). Strategi Pemberdayaan Kelembagaan Petani. Forum Penelitian Agro Ekonomi, 26 (2): 82-91.

Surya, M. A., (2012). Evaluasi Kebijakan Pajak Pertambahan Nilai Atas Feed Additive. Thesis. Universitas Indonesia.

Stufflebeam, D. L. (2003). The CIPP model for evaluation. Presented at the 2003 Annual Conference of the Oregon Program Evaluators Network (OPEN) (Chapter 2). Boston, MA: Kluwer Academic Publishers.

Zhang, G., Zeller, N., Griffith, R., Metcalf, D., Williams, J., Shea, C., \& Misulis, K. (2011). Using Context, Input, Proses, and Product Evaluation Model (CIPP) as a Comprehensive Framework to Guide the Planning, Implementation, and Assessment of Service-learning Programs. Journal of Higher Outreach and Engagement, 15 (4), 57-83. 